
PP Periodica Polytechnica
Architecture

48(1), pp. 65-71, 2017

https://doi.org/10.3311/PPar.11037

Creative Commons Attribution (i)

RESEARCH ARTICLE

\section{Improving the Effectiveness of Public Spending on Transport Infrastructure}

\author{
Radan Tomek ${ }^{1 *}$
}

Received 28 February 2017; accepted 30 March 2017

\begin{abstract}
The highways network is the backbone of every national transport system and plays a strategic role in a country's economic development. With regards to the large investments, operational and maintenance costs that it requires, sound asset management and a thorough economic appraisal of investments are of high importance. Therefore, it is appropriate to analyse and possibly modify existing methods for evaluating the economic efficiency of road construction and asset management at the scientific level, with the support of the real practice experience. Our research concentrates on an evaluation of the current approach to the asset management of the transport infrastructure, methods of economic appraisal, their consecutive improvement, incorporation of the LCCA agenda and an evaluation of environmental and social aspects in the investment decision process. Consequently, it focuses on the possibilities for improving the effectivity of these aspects through the proposal of very concrete measures based on the results of our research and the experience of real practice management construction.
\end{abstract}

\section{Keywords}

economic efficiency, asset management, investment appraisal, life-cycle costs, HDM-4 software, road transport infrastructure

\footnotetext{
${ }^{1}$ Department of Construction Management and Economics, Faculty of Civil Engineering,

Czech Technical University in Prague

Thákurova 7, 16629 Praha 6, Czech Republic

*Corresponding author, e-mail: radan.tomek@fsv.cvut.cz
}

\section{Introduction}

This research paper deals with the major deficiencies in the current investment decision processes of the highway network, with the major problems and ineffectiveness in the consecutive phase of realisation and the subsequent effort required to manage all the assets properly. The overall approach of this research paper is to examine the possibilities for improving the effectiveness of this investment decision process and realisation phase through the proposal of very concrete measures. In substance, it concerns the purposeful synthesis of proper asset management with a more effective investment programme to achieve higher infrastructure quality. Although this paper depicts the current road infrastructure situation in the Czech Republic, talks about local state offices and agencies and uses local transport infrastructure data, it also analyses global experiences; its findings aspire to be of general validity and applicability.

Current importance of this topic is also given due to the currently increasing production of the construction segment and the present situation of financing the construction of roads and highways. Regarding the volume of investments, it is favourable mainly due to various European Union funds (Cohesion Fund and European Regional Development Fund). These funds are primarily to support routes, which should become part of the Trans-European Transport Networks (TEN-T). Czech Republic has committed to complete the TEN-T routes' infrastructure by 2030. This is to be carried through the European Union's framework of Transport Operational Programme. This means, that until 2030 Czech Republic should almost double the length of its motorway and highway network - from the actual $1242 \mathrm{~km}$ to $2180 \mathrm{~km}$. Unfortunately, availability of these European Union resources to such an extent is limited by the year 2023 (MDČR, 2015). To secure the sustainability of the development to the pre-set speed of the construction even after this date, when financial resources will rapidly decrease, a significant change in the overall approach and consequently a significant increase in effectiveness is needed. This can be achieved only through increased emphasis on economic, procedural and managerial aspects of both phases of road infrastructure construction - the investment decision process and construction realisation phase. 
To achieve a better understanding of the current practice of appraisal of the economic effectiveness of highway (respectively road) projects, we also analyse one such appraisal - an output of widely used HDM-4 software and the way its results are understood and interpreted.

\section{Approach to economic appraisal of the investment}

Based not only on the vast experience of the American and Czech state highway agencies, the main goals and areas to be considered during the highway investment's economic effectiveness appraisal are as follows:

- transportation system efficiency - improvement of its reliability and efficiency;

- cargo movement and support for economic development - improvement of the road network capacity and regional interconnection;

- traffic safety - to significantly reduce human fatalities and injuries due to traffic on all roads;

- traffic congestion reduction - significant reduction of congestion on the road system;

- infrastructure asset development - maintenance, repair and rehabilitation strategy of all roads and structures;

- environmental impacts - minimise the impact of transportation on nature, environment and population (FHWA, 2014).

Without proper consideration of all these criteria, the investment decision-making process cannot be complete.

The current method for evaluating the economic efficiency of road construction is carried out using the methodology of the Czech Road Assessment System (CSHS). For the actual economic assessment, CSHS methodology is determined by the software tool HDM-4, developed by Birmingham University (United Kingdom) with support from the World Bank (Čihák et al., 2013). Thanks to its complexity and flexibility to include a high number of factors and inputs, this software is used in many European countries (Schneiderová Heralová, 2011).

However, there is a significant problem to this widely used assessment tool - or, possibly, a problem of this whole assessment approach. It also has to implement data and information that are more of a qualitative and sometimes even intangible nature -it is very hard to quantify the value of safety, human life or environmental impact. Although, the tool works mainly with the data of a quantitative kind, more appropriate for economic appraisal. However, very often it is that small portion of mentioned soft data that can change the whole result of the analysis and the choice of the accepted variant of the projected investment. The result of the analysis is very sensitive to these data inputs and can be influenced marginally by an artificial change in these qualitative indicators. Such a possibility to affect an overall result of the analysis by "tweaking" mentioned soft data is a major problem itself. An analyst should not have the option to decide over the results of the analysis. Based on the above, it seems that toFig achieve a reasonable level of comparability of individual investment projects, it is necessary to standardise the quantification and financial appraisal of these qualitative/ intangible criteria.

It is not only the intangible nature of such inputs that need to be processed for a quality and complex evaluation of the economic effectiveness of an investment project; the assessment of environmental and social (E\&S) costs associated with both highway construction and rehabilitation operations is faced with several further challenges as Surahyo and El-Diraby (2009) suggest:

- Lack of clear definitions: there is no clear and agreed upon definition of the E\&S costs. This could be attributed to the subjectivity of the domain itself and the fact that this is an evolving domain of interest to decision makers;

- Ambiguity in identifying relevant costs: there are no standard means to identify which costs apply to each project. There is also no clear means to link specific project tasks to certain environmental/social impacts;

- Unclear boundaries: there is no agreement on the geographical extent of the E\&S impacts of highway construction. While some researchers have considered the macro/global impacts, others have only considered the micro/immediate impacts;

- Inconsistent estimation methods: some methods use socio-economic approaches, while others use pure technical/engineering approaches. There is a clear inconsistency in the methods used by researchers and practitioners to estimate these costs. This is not simply due to the subjectivity of the domain, but is also a reflection of the disagreement on the extent of the impacts of a highway project on the surrounding environment;

- Every project takes place in different environmental and social conditions, and so the E\&S impacts will also differ as will the costs. It is, therefore, unfeasible to develop a universal standard to address the challenges above, especially research and implementation assessing and mitigating E\&S impacts, which are still evolving. An important step towards establishing more rigorous solutions to the challenges of E\&S impacts is to consistently and effectively document knowledge gained by researchers and practitioners in dealing with them.

Considering these points and that every single project's E\&S factor entering the economic evaluation will be, to a certain extent, different, creating a database that would allow the collection of both - all the practically discovered and theoretically expected/ calculated costs - would be a good step to make economic evaluation more precise and comparable between each other. 
Table 1 HDM-4 output (in millions CZK; source: own research)

\begin{tabular}{|c|c|c|c|c|c|c|}
\hline \multirow[b]{3}{*}{ Year } & \multicolumn{6}{|c|}{ Zero Variant (currents state) } \\
\hline & \multicolumn{6}{|c|}{ Costs } \\
\hline & Managment & Operational & Travel Time & Accidents & Extermalities Total & Total \\
\hline 2016 & 0.79 & 19.32 & 18.26 & 1.62 & 7.02 & 47.01 \\
\hline 2017 & 0.65 & 18.76 & 17.53 & 1.57 & 6.65 & 45.16 \\
\hline 2018 & 2.48 & 18.03 & 17.22 & 1.50 & 6.35 & 45.58 \\
\hline 2019 & 0.61 & 17.48 & 16.65 & 1.47 & 6.01 & 42.22 \\
\hline 2046 & 0.16 & 5.51 & 5.36 & 0.46 & 1.59 & 13.08 \\
\hline 2047 & 0.14 & 5.21 & 5.15 & 0.44 & 1.52 & 12.46 \\
\hline 2048 & 0.14 & 4.70 & 4.89 & 0.42 & 1.44 & 11.59 \\
\hline \multirow[t]{3}{*}{ Total: } & 15.28 & 362.36 & 349.88 & 30.78 & 115.56 & 873.86 \\
\hline & \multicolumn{6}{|c|}{ Proposed Variant } \\
\hline & \multicolumn{6}{|c|}{ Costs } \\
\hline Year & Management & Operational & Travel time & Accidents & Extermailities Total & Total \\
\hline 2016 & 18.72 & 19.32 & 18.26 & 1.62 & 7.02 & 64.94 \\
\hline 2017 & 47.60 & 18.76 & 17.53 & 1.57 & 6.65 & 92.11 \\
\hline 2018 & 39.20 & 18.03 & 17.22 & 1.50 & 6.35 & 82.30 \\
\hline 2019 & 0.87 & 17.02 & 13.06 & 1.62 & 2.65 & 35.22 \\
\hline 2046 & 0.21 & 5.41 & 4.20 & 0.59 & 0.74 & 11.15 \\
\hline 2047 & 0.20 & 5.10 & 4.01 & 0.49 & 0.71 & 10.51 \\
\hline 2048 & -6.66 & 4.59 & 3.80 & 0.46 & 0.69 & 2.88 \\
\hline \multirow[t]{4}{*}{ Total } & 116.27 & 353.67 & 286.66 & 33.85 & 62.05 & 852.50 \\
\hline & & & & & Net Present Value & 10.90 \\
\hline & & & & & Internal Rate of Return & $6.10 \%$ \\
\hline & & & & & Benefit-Cost Ratio & 1.2115 \\
\hline
\end{tabular}

\section{Assessment tool HDM-4}

Birmingham University developed the HDM-4 software with support from the World Bank (WB). Its primary task is to assess the economic efficiency of transport infrastructure projects, but thanks to the comprehensive evaluation, it also includes other modules focused on technical aspects of the project. From an economic point of view, the software is based on the principle of comparing zero variants (current status) with new variants, compared to main economic indicators as follows:

- Net Present Value (NPV),

- Internal Rate of Return (IRR),

- Benefit-to-Cost Ratio (BCR).

Coming out of these standard and widely recognised indicators, we can compare two or more options and decide on the most effective solution. Overall assessment of the project is primarily based on societal benefit (Schneiderová Heralová, 2015). Thus, the actual assessment will also include costs that are not only of an investment and operational nature, i.e. of qualitative/intangible nature as mentioned before, but which represent a significant problem regarding their valuation.

From an economic standpoint, the most interesting output from HDM-4 is the sum of the project's discounted flows. An example of such an output is shown in Table 1 below. There are two basic groups of costs. The first group consists of costs associated with the transport route's operation. These are mainly the costs of maintaining the roads, traffic vehicles (fuel, spare parts), accidents (material damage and human injury) and travel time. In the second group, there are costs (externalities) related to environmental impacts. These are the costs of air pollution, excessive noise and exhaust fumes $\left(\mathrm{CO}_{2}\right)$.

Table 1 represents an example comparing the two variants of the project. It compares the baseline scenario, i.e. how the situation without the projected changes and the proposed variant, which represents an investment opportunity. This project is the construction of a 4-km village bypass with the necessary antinoise measures (barrier). Construction costs were roughly determined to CZK 110 million. Other necessary information was obtained using the combination of data from the Czech state highway agency ( $\breve{\mathrm{R} S D}$ ), HDM-4 and the Exnad model to calculate the externalities. The project was evaluated for a 30 -year period of operation. The main criterion for assessing whether the project is economically viable is an indicator of IRR, which has to reach a greater value as the discount rate itself. During evaluation of the project (resp. of the proposed variant), IRR reached $6.1 \%$, while the fixed discount rate was at $5.5 \%$. This made the proposed variant acceptable and meant that it represented savings for the whole society, ultimately resulting in the project's implementation. 
The decisive moments of the overall evaluation of this variant were the total time savings found, the reduction of noise pollution and general environmental impact.

The very tight result also proves the previously mentioned problem of sensitivity of the qualitative and intangible data valuation with this appraisal approach. Subjective valuation of such inputs represents a danger to the whole otherwise very sophisticated tool and approach.

A possible way of making the factors mentioned above, entering the evaluation, more precise is through their unification, respectively their comparability to the greatest extent possible, as proposed above.

Practical means to achieve this and to make the desired economic evaluation's criteria more exact is to create a database of all the costs of this nature that would be accessible for all involved parties. A technical solution via an online accessible database is probably the most practical if it would allow users not only to access all the data (i.e. its costs) similar to their individual project but also to contribute to the database by uploading and sharing their data.

\section{Life-cycle costs analysis}

The life-cycle cost analysis (LCCA) technique is commonly accepted as a useful investment/project evaluation tool. LCCA one of the most current topics not only in road construction. It evaluates the costs associated with the project from its initial preparation until its dissolution. It helps to find the optimal variant of the project throughout its life-cycle. Complex LCCA reflects all the economic variables fundamental to the evaluation - user costs like travel time consumption/delay, safety costs connected with maintenance and rehabilitation projects, agency capital cost, and life-cycle maintenance costs. The need to optimise the cost of construction and operation in the current environment of rising energy prices and the deepening pressure on savings and cost-cutting is increasingly popular. The standard means for determining the LCCA is the Net Present Value (NPV), which represents the present value of future costs incurred during the project's life-cycle; as an optimal variant from the assessed scenarios, it is that with the lowest final present value of future costs. However, there is a problem with selecting an appropriate discount rate, in addition to some technical problems with the LCCA's implementation. Acquiring credible supporting data and information, including the data on traffic or projecting future traffic flows are one of them. Despite such technical difficulties, the limited research carried out and the understanding achieved of this complex concept, the LCCA has the potential to provide us with valuable data and conclusions.

Fig. 1 shows the LCCA of the new motorway sections in the Czech Republic (without the liquidation phase). In the transport infrastructure construction - unlike in conventional building or heavy construction - the largest costs are associated with the investment phase of the life-cycle. The fact that roughly two-thirds of all the costs are connected with the project's capital investment phase gives us a great opportunity to reach significant savings exactly through increasing the effectiveness of the investment decision process and the design and construction realisation phase.

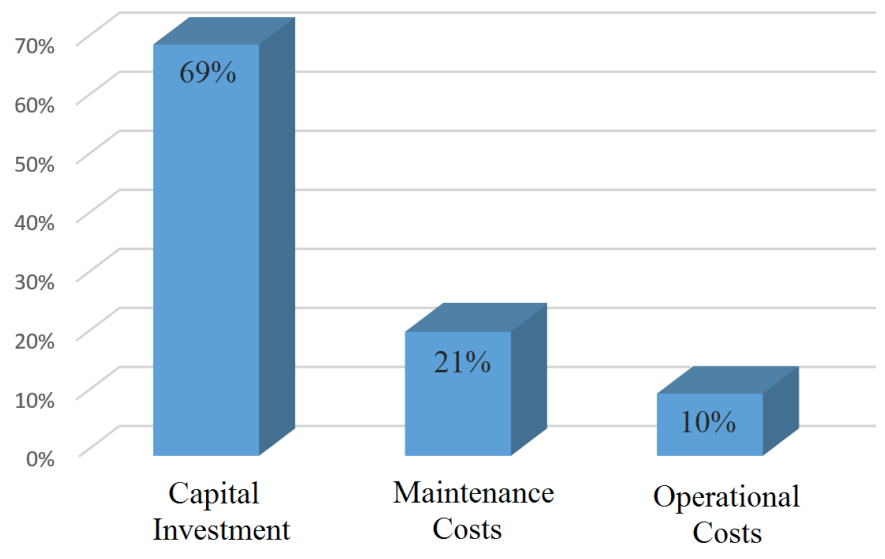

Fig. 1 Life-cycle costs in highway infrastructure construction (source: own research)

\section{Effectiveness of the realisation phase}

Disclosing the infrastructure projects' construction business, it is essentially a very attractive business because of the relative ease of achieving extraordinary gains. It derives from the principles of the "measured contract" when the price of the executed work is determined by multiplying the price per unit and the number of these units made (Hromada et al., 2014). This approach applies to civil engineering in general.

It is the work not really executed that can be the source of above-average profit. This is the case when reported quantities are larger than actual and where there is an artificial increase in unit prices through change management. For example, a very common situation - billing for the extraction and transportation of 150 thousand $\mathrm{m}^{3}$ of soil instead of the actual amount carried out, say 100 thousand $\mathrm{m}^{3}$. Also, not for the contractual unit price per $\mathrm{m}^{3}$, but for the price, increased via change management for inclusion into another class workability (e.g. due to different geological conditions).

Such behaviour patterns of the suppliers of engineering structures can be quite effectively faced with a combination of these essential measures that we propose and methods and practices, time-proven in the rest of the world:

- Flawless project documentation incorporating maximal standardisation of all the project's sections (especially those most costly, when designed and built/produced, i.e. bridges, tunnels and anti-noise barriers). Thorough digital scanning of the terrain and application of Building Information Modeling (BIM) to not to leave much space for any major contract changes during construction. Regular/ repetitive frequency of such three-dimensional scanning is also a way to gain an overview and control of actually 
processed quantities (of soil, for example) and a chance to increase fairness of billing with the contractors;

- Correct cost estimate of all individual items (control budget) of the design based on an exact bill of quantities prepared by the Highway Agency itself and based on its own cost database (i.e. outsourcing of any of these activities being unacceptable, e.g. using designer's bill of quantities). Consecutive realisation phase being in accordance with accepted cost estimates and bill of quantities. Project manager's personal responsibility for these tasks being of crucial importance;

- Evaluating competing bids based on the state agency's own flawless control cost estimate (budget) and rejecting those bids of abnormally low or high values $( \pm 10-15 \%$ against the control budget). Such an approach also eliminates most of the bidders' reasons to appeal against the results of the tender;

- Objective, independent and incorruptible execution of own technical supervision (supervisor/engineer) regarding performed quantities and approved changes to design during the realisation phase;

- Confirmation of performed quantities and approved changes to design during the realisation phase by an independent authorised subject (quantity surveyor / technical supervisor) beyond the usual extent. An additional thirdparty subject with the lowest possible probability of ties with the contractor is financially favourable especially on larger projects;

- In a sensitive area of environmental protection, a clear need for many environmental measures is often a matter of opinion and is hard to determine with certainty. At the same time, such measures are often financially demanding. To counter the above mentioned with financial responsibility and to act in accordance with valid EU directives, an investor should choose an approach of so-called Adaptive Management;

- Applying any environmental protection measures or design variations based on the proportion of probability of a phenomenon and not in the form of a precaution holds potential for significant savings in comparison to current practice;

- Legal option to foreclose from any further new project tenders those contractors that are in any form of dispute over any past project with the state. Although this principle has proven its efficiency in various states in Europe, it is still not being implemented into the legal codes for public contracts of most of the states. When implemented and practised, it significantly improves the bargaining position of the state. It also fundamentally regulates the behaviour of contractors towards the state agencies, bringing it closer to the standards of behaviour/relationships of the owner-contractor in the private sector.

\section{Asset Management System}

There are various types of assets that a public transportation agency needs to manage to meet the needs of their founders and users, i.e. to meet public, agency, and legislative expectations in general. Physical transportation infrastructure is, without doubt, the most obvious one, but agency's human resources, know-how and experience, financial capacity, real estate, materials stocks, equipment and vehicle fleets, and corporate organisation, data and information also need to be optimally managed. The referred to a variety of transportation infrastructure and its administrating public agency's assets, make their management (further unified under a Transportation Asset Management term or TAM abbreviation) a task requiring a truly strategic approach. That infrastructure assets serving the public can also be owned and managed by private enterprises is not further researched in this paper as it is not subject to public spending in a continuously managerial/administrative meaning.

No matter what country's transport network needs to be dealt with, the objectives and benefits of asset management implementation are:

- To build, preserve, operate, and reinvest in facilities more cost effectively with improved performance;

- To deliver to an agency's customers the best value for the public tax money spent;

- To enhance the credibility and accountability of the transportation agency to its governing executive and legislative bodies.

To successfully meet all these obligations, needs a system so that, in turn, all the following activities and duties are met. These range from initial information acquisition, planning and programming to the execution of new construction, its maintenance, rehabilitation and renovation; or from the details of individual project design and construction to periodic in-service monitoring and evaluation and financial management. According to Uddin et al. (2013), such a system should ideally coordinate and enable the execution of all activities so that optimum use is made of the funds available while maximising the performance and preservation of infrastructure assets and provision of services. It would serve all management levels in the organisation (public or private) and would be structured to be adaptable to all of its infrastructure. In other words, it would be general in scope and incorporate particular models, methods, and procedures needed for specific types of infrastructure.

In the past, several years, transportation agencies throughout the world have engaged a more strategic view of managing facilities, referred to as transportation asset management. Transportation asset management drives a more broadly defined, strategic approach to resource allocation decisions across all transportation assets. It provides a framework for an agency to make decisions on investments in new capacity, improvements, preservation, and operations based on better information and 
in a more holistic and proactive way. Asset management helps build a financial awareness of the importance of transportation assets, economically, socially, and technically. It represents fundamental principles of good practice that can be applied by agencies representing different organisational structures, management philosophies and culture, demographic and geographic influences on transportation demand, funding situations, and institutional relationships (NCHRP, 2002).

However, transportation asset management entails more than just a mixing of existing procedures or compilation of existing data. A comprehensive asset management approach may entail change in how an agency conducts business, reaches decisions, collects and processes data, and communicates information. Good asset management thus requires a strong technical and informational basis that supports effective business processes and well-functioning channels of communication within the agency's organisation and with external policy bodies, customers, and other interested parties (NCHRP, 2002). There are also many external factors affecting TAM system like budgets, decision criteria and maintenance policies, together with non-quantifiable agency policies, including political climate, environmental stewardship, and sustainability considerations (Surahyo and El-Diraby, 2009).

Implementation of a proper transportation asset management system will surely provide many benefits through decreased costs on operational and maintenance expenses, bringing economical solutions, delivering better service to the public (i.e. its users), and bringing increased management accountability. Nevertheless, according to the research conducted for the American State Highway Agency (NCHRP, 2002), its implementation will be problematic in any state's conditions, with the following main obstacles, both institutionally and technically.

Institutional Challenges

- To integrate decision-making and allocation of resources across asset classes.

- To combine the financial, management, engineering, and operational perspectives of a department within this decision process.

- To define system performance measures that reflect customer perspective and user costs effectively.

- To secure senior management support and leadership throughout the period of asset management implementation, which may extend over several years.

- To develop new public and private sector roles that enable an agency to fulfil its mission in the face of change, and to implement these roles effectively.

- Technical Challenges

- To integrate legacy systems and stand-alone databases established for individual asset classes or functions.

- To develop comprehensive, GIS-compatible, enterprise-wide databases that better serve asset management.
- To create next-generation management systems or specialised analytic tools that support a wide range of what-if analyses reflecting different budget and performance assumptions (e.g., for trade-off analyses).

- To improve life-cycle analysis methods and incorporate them fully within planning and programme development.

- To strengthen transportation system monitoring capabilities and use of this information for programme evaluation and policy formulation.

For the administrating agency to be successful in infrastructure asset management in general, above the stated challenges, are those issues that it needs to overcome to successfully implement a properly functioning transportation asset management system and so to become economically effective in this area of public spending.

\section{Summary and conclusions}

There are significant inefficiencies in the current decision process regarding investments in the road network. There are different methodologies in the investment decision process (based on a location), but for the actual economic assessment of the project, it is the software tool HDM-4, which is most widely used. Thanks to its complexity and flexibility to include a high number of factors and inputs, we have found this tool as suitable and verified in a case study. However, the main deficiency found was not found to the software but to the general approach to the assessment within every investment unit (i.e. resort or a country). The main inconsistency is in the various types of data that have to be processed. Both, standard technical and financial data and at the same time information that is of a qualitative and intangible nature have to be included in the decision process. Though technically possible, different results based on the latitude of input data values are the problem. This is due to inconsistency in the valuation of those qualitative/ intangible data. It is only proper and consistent unification of this valuation for all the projects assessed within every investment unit/area/country, that can improve inter-comparability and quality of the resulting investment decision. Based on the above said, it is evident that to achieve a decent level of comparability of individual investment projects, it is necessary to standardise the quantification and financial appraisal of these qualitative/intangible criteria. A possible way to unify and so make such evaluation criteria more exact is to create a database of all the costs of this nature, which would be accessible for all involved parties. Technical solutions via a generally accessible database are probably the most practical if it allows all its users to not only access information (i.e. its costs) of all other evaluated projects but also to share their data, results and findings.

Further analysing the structure of the life-cycle costs in highway construction projects, we affirmed that complex 
life-cycle cost analysis technique has the potential to provide us with valuable data and conclusions. The fact that roughly two-thirds of all the costs are connected with the project's capital investment phase evidently represents a great opportunity to reach significant savings through an increased effectiveness of the investment decision process and design and construction realisation phase.

Regarding the realisation phase of the road infrastructure investment project, we targeted major problems and ineffectiveness. Based on the practice of project management in this type of project, we summarised the areas that lead to economic inefficiency most often. We proposed a set of essential measures, methods and practices to face them effectively. Those of being highest importance are as following:

- flawless project documentation incorporating maximum standardisation, thorough digital scanning of the terrain and application of Building Information Modelling; to decrease the volume of major contract changes during construction, and increase control of actually processed quantities and to increase fairness of billing;

- investor's control budget prepared based on his bill of quantities and cost database; project manager's personal responsibility for the control budget and its accordance with the consecutive realisation phase;

- evaluating competing bids based on the investor's flawless control budget and rejecting those bids of abnormally low or high values by a pre-set strict rule;

- execution of own technical supervision, i.e. no outsourcing being acceptable for this task;

- if needed, employment of an additional third-party authorised subject for the higher-level technical supervision;

- applying any environmental protection measures or design variations based on the proportion of probability of a phenomenon and not in the form of a precaution;

- legal option to foreclose from any further projects tenders those contractors that are in any form of dispute over any past project with the state to significantly improve the bargaining position of the investor and to standardise contractors' behaviour towards him.

\section{References}

Čihák, M., Hak, F., Hladká, J., Horníček, K., Kubešová, S., Mátl, R., Michková, V., Šrajerová, J., Vorel, V. (2013). Páteřni sit’ silnic a dálnic v Č́R (Road and Highway Backbone Network of the Czech Republic.), Prague, Agentura Lucie. (in Czech)

FHWA - The Federal Highway Administration (2014). Advancing a Sustainable Highway System: Highlights of FHWA Sustainability Activities. URL: https://www.sustainablehighways.dot.gov/FHWA_Sustainability_Activities_June2014.aspx

Hromada, E., Schneiderová Heralová, R., Johnston, H. (2014). Cost Structure of the Highway Projects in the Czech Republic. Procedia Engineering, 85, pp. 222-230. 2014. https://doi.org/10.1016/j.proeng.2014.10.547

MDČR - Ministry of Transport of the Czech Republic (2015). MD chystá start PPP projekti̊ v dopravnívýstavbě, využit je chcena $R 4$ a $R 7$ [cit. 2015-11-19] (Ministry of Transport's preparation for the use of PPP projects in transport infrastructure construction). Webpages of Ministry of Transport of the Czech Republic. URL: https://www.mdcr.cz/Media/ Media-a-tiskove-zpravy/MD-chysta-start-PPP-projektu-v-dopravnivystavbe (in Czech)

NCHRP - National Cooperative Highway Research Program (2002). Project 20-24(11) - Task 1: Synthesis of Asset Management Practice, Task 2: Asset Management Framework. URLs: http://onlinepubs.trb.org/onlinepubs/nchrp/nchrp_w41_task1.pdf and http://onlinepubs.trb.org/onlinepubs/nchrp/nchrp_w41_task2.pdf

Schneiderová Heralová, R. (2011). Udržitelné pořizováni staveb: ekonomické aspekty. (Getting Structures Sustainable: Economic Aspects; in Czech lang.). Prague, Wolters Kluwer Česká Republika. (in Czech)

Schneiderová Heralová, R. (2015). Highway Projects: Prices in Public Bids. Procedia Engineering. 123, pp. 496-503. https://doi.org/10.1016/j.proeng.2015.10.101

Surahyo, M., El-Diraby, T. E. (2009). Schema for Interoperable Representation of Environmental and Social Costs in Highway Construction. Journal of Construction Engineering and Management. 135(4), pp. 254-266. https://doi.org/10.1061/(ASCE)0733-9364(2009)135:4(254)

Uddin, W., Hudson, W., Haas, R. (2013). Public Infrastructure Asset Management, 2nd ed., McGraw-Hill Education. 